\title{
Exploration and Thinking of Online and Offline Mixed Teaching Mode in the Teaching of Ship Fluid Mechanics
}

\section{Zongmin Li}

School of Marine Engineering, Jimei University, Xiamen 361021, Fujian Province, China

\begin{abstract}
This paper has analyzed the advantages of the online and offline mixed hybrid teaching mode in its teaching. According to the current teaching situation of ship fluid mechanics, through the exploration of online and offline teaching mode in the teaching of ship fluid mechanics, this paper has discussed the application methods of online and offline mixed teaching mode in the course of ship fluid mechanics, including teaching content design, teaching method design and teaching evaluation design Aspects of the method. Through the preliminary application, some implementation effects have been achieved and the teaching quality has been improved to a certain extent.
\end{abstract}

Key words: Mixed teaching mode; Teaching ideas; Teaching content; Teaching method; Teaching evaluation

Publication date: December, 2020

Publication online: 31 December, 2020

"Corresponding author: Zongmin Li, 76271376@ qq.com

With the development of information technology and computer technology, the development of teaching mode is also changing. The emergence of online education greatly facilitates the community to learn a variety of professional knowledge, but also has a great impact on college teaching. Colleges and universities have launched online education courses and online and offline hybrid education courses to facilitate students to learn anytime and anywhere, and improve learning effect and teaching efficiency ${ }^{[1]}$.

The traditional teaching mode is not conducive to the understanding and mastery of knowledge, and it is urgent to reform the traditional teaching mode, because teachers teach in full house and students learn mainly by mechanical memory. Therefore, in the teaching of marine fluid mechanics, MOOC online course resources of China University are selected to explore the online and offline hybrid teaching mode. The use of online resources fully realizes resource sharing, and students can experience the high-quality educational resources from other colleges and universities, and the learning is flexible, convenient and repeatable. The online and offline teaching content is effectively integrated through the teaching form of flipped classroom, which is explored and discussed in the teaching of ship fluid mechanics $^{[2]}$.

\section{Basic information of the course}

The course of ship fluid mechanics is a professional basic course for undergraduates majoring in ship and ocean engineering. The traditional teaching method is still used in the course teaching. It's lack of personalized teaching for students, not fully considering the individual differences of students. The teaching process is lack of innovative ideas, less integration of modern teaching methods, less application of network platform, modern teaching tools and teaching methods of intelligent teaching.

\subsection{The teaching content is rich and boring.}

The teaching content of this course covers a relatively wide range ${ }^{[3]}$. At present, teachers mainly focus on the content of teaching materials, and the teaching content is boring. Especially in the teaching process, the same teaching method is adopted for students, the same information is transmitted with the same progress, all students are synchronized, and the unity 
is emphasized. In fact, this kind of teaching method violates the principle of individual differences of students, which makes students lose the motivation of learning, and the effect of classroom learning is general $^{[4]}$.

\subsection{Teachers are the center of teaching activities.}

In the teaching process of marine hydrodynamics, the teaching activities are basically arranged by teachers. The main teaching activities are teachers' explanation of theoretical knowledge, supplemented by students' autonomous learning, so students' participation in class is not high. This traditional teaching mode seriously ignores the main position of students in the teaching process, makes students have the illusion of "staying out of the way", reduces their interest in learning and makes them feel boring and boring in their learning process.

\subsection{Knowledge based and lack of innovation}

As the classroom teaching is mainly to impart knowledge and skills, students have not formed the habit of autonomous learning and inquiry. Although students have gained a lot of knowledge in class, it is not known whether they can internalize it into their own knowledge. In addition, the traditional curriculum assessment method focuses more on the final examination results, too much emphasis on the evaluation of the course after the end of the course, overemphasizes the summative evaluation, and lacks the assessment of multiple learning processes. Therefore, this traditional teaching mode violates the educational principle of teaching students in accordance with their aptitude, and the assessment method can not truly reflect the students' problemsolving ability and real level. In order to improve the teaching effect, we must pay attention to the students' subjective initiative, innovate the teaching mode and optimize the teaching structure.

\section{Mixed teaching ideas}

The course of marine fluid mechanics adopts the mixed teaching mode of online and offline. In the teaching design, the individual differences among students are fully considered, and the students are the center, and the teaching is hierarchical, differentiated and diversified. The evaluation of teaching effect pays attention to the cultivation of students' ability. The online and offline assessment is carried out at the same time. The assessment is carried out in stages when the course is carried out, and then the comprehensive evaluation is carried out after the course is finished, so as to promote the deep integration of modern information technology and classroom teaching.

\subsection{Teaching students according to their aptitude}

The design of teaching methods reflects teaching students in accordance with their aptitude. In accordance with the principle of student-centered, different teaching methods are designed for different basic students in our school, focusing on the important role of information technology in improving the understanding of teaching content. Each student has different receptivity and understanding. For the same knowledge point, students with strong receptive ability and understanding ability need to read it once to fully understand and master it, while students with poor foundation have poor receptive ability and understanding ability, and may need to look over and over again to fully digest and understand. In view of individual differences, we can use the advantage of online teaching content to review. Different students can combine their own situation to achieve basically the same learning effect for the same knowledge point through different class hours.

\subsection{Combination of learning and thinking, unity of knowledge and practice}

Learning without thinking is futile; thinking without learning is perilous. After students acquire knowledge through necessary learning in class, they must think about it, digest and absorb it, internalize it into their own things, guide their actions with the knowledge they have learned, and achieve the unity of knowledge and practice. This idea can be realized by online teaching platform before, during and after class. Before class, a short preview courseware can be arranged to enable students to understand the classroom teaching content in advance, actively think about the knowledge points that are not easy to understand, and help teachers to timely understand where the students' problems are by checking the preview situation, and effectively grasp the key points and difficulties of teaching in class; in class, the realtime interactive function of online platform can be used to appropriately ensure the safety of teaching The methods of arranging small-scale interactive questions, random roll call questions, students' 
questions and answers, and students' lectures and students' evaluation can promote students to follow the classroom teaching ideas, constantly think, and constantly obtain cognition; after class, through the arrangement of thinking questions, personal assignments, group work, etc., to promote the discussion and communication between students, and pay attention to the formation and improvement of students' ability of cooperation, exploration and innovation.

\subsection{Inspiration and guidance, step by step}

In the process of teaching, according to the teaching task and the objective law of learning, starting from the reality of students, teachers adopt various ways to stimulate students' thinking as the core, mobilize students' learning initiative and enthusiasm, and promote them to learn lively. The teacher's inspiration is based on students' thinking. After inspiration, students should be allowed to think again and get further understanding. The teaching should be from the simple to the deep, from the easy to the difficult, by analogy. Some open questions can be set in teaching to give students a big direction to think, and the more specific answer is to be obtained by the students themselves. Build a ladder for students to enhance their academic challenge.

\section{Mixed teaching curriculum design}

\subsection{Design of teaching content}

Teaching content is the main information that is intentionally transmitted in the process of interaction between learning and teaching, generally including curriculum standards, teaching materials and courses, etc. For the new online and offline hybrid teaching mode, the key and difficult points of each chapter of the course are sorted out, the knowledge points of the course are refined again, the teaching plan is rearranged, and the asynchronous SPOC is carried out in combination with the imported national excellent courses to integrate the knowledge points.

\subsection{Design of teaching methods}

Teaching methodology consists of guiding ideology, basic method, concrete method and teaching method. Teaching methods include two aspects: Teachers' teaching methods (teaching methods) and students' learning methods (learning methods), which are the unity of teaching methods and learning methods.
The teaching method must be based on the learning method, otherwise it will not be able to achieve the expected goal effectively due to the lack of pertinence and feasibility.

With the development of science and technology and computer technology, people's demand for knowledge anytime and anywhere increases. MOOC, an online education mode, has gradually formed and entered people's lives ${ }^{[5]}$. The emergence of online education provides a lot of convenience for people's learning, but at the same time, it also has a great impact on the teaching of colleges and universities, and it is also a great test for the majority of teachers. Online and offline hybrid teaching mode has been vigorously promoted in Colleges and universities. SPOC (small private online course), namely smallscale restricted online course, is a small-scale and restrictive mixed teaching mode integrating online courses and offline entity courses. It realizes the introduction of high-quality MOOC resources into the physical classroom, so as to expand the classroom knowledge capacity, deepen the face-toface communication between teachers and students, so as to improve the teaching quality ${ }^{[6-8]}$. This course has established asynchronous SPOC course, which continuously improves and supplements the teaching content on the basis of the shared national essence course. Students can be exposed to the outside world.

\subsection{Design of teaching evaluation}

The traditional assessment methods rely too much on the final examination results, and the usual results are not objective enough. After the combination of online and offline evaluation methods, the online teaching platform can be used to timely check the learning data, master the participation of students in attendance, interaction, testing, etc., assign homework questions, after-school thinking questions, praise the advanced and urge the backward. Star award should be given to the students who actively participate in the interaction in class, and the announcement should be sent out in time. This makes the formation of the ordinary performance of the course more objective and fair. Online platform can well record and reflect how much time and energy students have invested in a course, and how much knowledge and skills they have learned. Everything is well documented and obvious to all. It is absolutely objective and fair. Students can deeply realize that "the more you give, 
the more you get."

\section{Conclusion}

Online and offline hybrid mode is the inevitable trend of future teaching. The traditional teaching mode must be integrated with modern technology and with the help of network platform. Of course, how to "mix" still needs time to think and practice. Only by constantly absorbing advanced teaching ideas in teaching practice, constantly exploring and thinking, and practicing, can we effectively use network technology and information technology, truly integrate online and offline, achieve complementary advantages, so as to achieve the best combination of online and offline teaching mode, make the course teaching become both vivid and interesting, students are willing to learn, love learning, and obtain teaching The learning effect is the best.

\section{References}

[1] Yin LP, Wang ST, Fang PY. Teaching exploration of "Introduction to aviation" course under online and offline mixed teaching mode [J]. Education Modernization, 2019,
97:213-215

[2] Sun L, Lang MF. Exploration and thinking of online and offline teaching mode in Physiology teaching [J]. Medical Education Research and Practice,2020,8(1): 76-80.

[3] Wang JM. Fluid mechanics [J]. Dalian: Dalian Maritime University Press, 2013:1-2.

[4] Wang YH. Exploration on the application of online and offline hybrid teaching mode in interior design teaching of higher vocational colleges [J]. Hunan Packaging Design Education, 2019, 34 (188): 121-124.

[5] Chen XG, Wang DM. Analysis of the development process and main characteristics of MOOC $[\mathrm{J}]$. Modern Educational Technology, 2013,23 (11): 5-10.

[6] Zhang F, Zou J. Practice and exploration of SPOC online and offline hybrid teaching mode in post MOOC era [J]. Journal of Hubei University of Economics (HUMANITIES AND SOCIAL SCIENCES), 2018,15 (11): 148-151.

[7] Tan SY. Research on ecological teaching mode supported by SPOC [J]. China Adult Education, 2016, (6): 100-103.

[8] Jing CQ. Exploration and Research on MOOC + SPOC online and offline Hybrid Teaching Mode -- Taking the public elective course of office automation in Wuwei Vocational College as an example [J]. Journal of Gansu Normal University, 2017,22 (9): 58-60. 